\title{
$\beta$-elemene enhances the antitumor activity of erlotinib by inducing apoptosis through AMPK and MAPK pathways in TKI-resistant H1975 lung cancer cells
}

\author{
Jue Wang ${ }^{1,2^{*}}$, Cong $\mathrm{Xu}^{1,2^{*}}$, Ying Chen ${ }^{3,4^{*}}$, Le Shao ${ }^{5^{*}}$, Ting Li ${ }^{1,2}$, Xingxing Fan ${ }^{1,2}$, Lili Yu ${ }^{1,2}$, Ruonan Zhang ${ }^{1,2,6,7}, \mathrm{Bi}$ \\ Chen ${ }^{1,2,6,7}$, Hongwei Chen 3,8 , Xinbing Sui ${ }^{6,7^{\bowtie}}$, Elaine Lai-Han Leung1, ${ }^{\bowtie}$ and Qibiao Wu ${ }^{1,2,9,10^{凶}}$ \\ 1. Faculty of Chinese Medicine, Macau University of Science and Technology, Taipa, Macau, China \\ 2. State Key Laboratory of Quality Research in Chinese Medicines (Macau University of Science and Technology), Taipa, Macau, China. \\ 3. Faculty of Medicine, Macau University of Science and Technology, Taipa, Macau, China. \\ 4. GCP center, the Affiliated Hospital of Nanjing University of Chinese Medicine, Jiangsu Province Hospital of Chinese Medicine, Nanjing, Jiangsu, China. \\ 5. The First Hospital of Hunan University of Chinese Medicine, Changsha, Hunan, China. \\ 6. Department of Medical Oncology, Holistic Integrative Oncology Institutes and Holistic Integrative Cancer Center of Traditional Chinese and Western Medicine, the \\ Affiliated Hospital of Hangzhou Normal University, College of Medicine, Hangzhou Normal University, Hangzhou, Zhejiang, China. \\ 7. Department of Cancer Pharmacology, Holistic Integrative Pharmacy Institutes, College of Medicine, Hangzhou Normal University, Hangzhou, Zhejiang, China. \\ 8. School of Public Health (Shenzhen), Sun Yat-Sen University, Shenzhen, Guangdong, China. \\ 9. Guangdong-Hong Kong-Macao Joint Laboratory for Contaminants Exposure and Health, Guangzhou, China. \\ 10. University Hospital, Macau University of Science and Technology Foundation, Taipa, Macau, China. \\ *Co-first authors with equal contributions to this work. \\ $\triangle$ Corresponding authors: Xinbing Sui (E-mail: hzzju@hznu.edu.cn); Elaine Lai-Han Leung (E-mail: lhleung@must.edu.mo) and Qibiao Wu (E-mail: qbwu@must.edu.mo).
}

(C) The author(s). This is an open access article distributed under the terms of the Creative Commons Attribution License (https://creativecommons.org/licenses/by/4.0/). See http://ivyspring.com/terms for full terms and conditions.

Received: 2020.09.17; Accepted: 2021.02.01; Published: 2021.02 .22

\begin{abstract}
Epidermal growth factor receptor (EGFR) tyrosine kinase inhibitors (TKIs) significantly improve the outcome of non-small-cell lung cancer (NSCLC) patients with EGFR mutations, however, most TKI-treated patients will develop resistance to TKIs. $\beta$-elemene, extracted from Curcuma aromatica Salisb., has been widely used to treat various malignant tumors, including TKI-resistant NSCLC, but, the effects and the molecular mechanisms remain unclear. In this study, the $\mathrm{NCl}-\mathrm{H} 1975$ cell line harboring double mutations L858R/T790M was treated with varying concentrations of $\beta$-elemene and/or erlotinib. The effects of $\beta$-elemene on cell proliferation, migration, apoptosis, and the expression of relevant proteins of $\mathrm{NCl}-\mathrm{H} 1975$ cells were evaluated. The results revealed that $\beta$-elemene significantly inhibited the growth, colony formation capacity, wound healing ability of $\mathrm{NCl}-\mathrm{H} 1975$ cells, and improved the sensitivity of $\mathrm{NCl}-\mathrm{H} 1975$ cells to erlotinib. Compared with erlotinib alone, $\beta$-elemene plus erlotinib significantly promoted the apoptosis of $\mathrm{NCl}-\mathrm{H} 1975$ cells, accompanied by the down-regulated expression of P-mTOR, P-EGFR, CHOP proteins and up-regulated expression of P-AMPK $\alpha$ and $\mathrm{Bax}$ proteins. Taken together, these findings demonstrate that $\beta$-elemene suppresses the proliferation and migration of TKI-resistant H1975 cells, and enhances the antitumor activity of erlotinib by inducing apoptosis through AMPK and MAPK pathways in TKI-resistant H1975 lung cancer cells, indicating that $\beta$-elemene is a promising anti-cancer therapeutic candidate for TKI-resistant NSCLC.
\end{abstract}

Key words: $\beta$-elemene; NSCLC; TKI-resistant; mechanisms; EGFR-mutated; AMPK; apoptosis

\section{Introduction}

Globally, lung cancer remains the commonest cancer and the leading cause of cancer death. Nonsmall cell lung cancers (NSCLC) is the most prevalent type, accounting for approximately $85 \%$ of lung cancers, and most newly diagnosed NSCLC patients are already at advanced stages $[1,2,3,4]$ when it is often too late for surgery. For the NSCLC patients with epidermal growth factor receptor (EGFR) mutation, tyrosine kinase inhibitors (TKIs) are the first-line treatment of choice [5] and greatly improve the outcome of patients. However, most TKI-treated patients will develop resistance to TKIs which is one of the most important causes of therapeutic failure $[6,7,8]$. Therefore, there is a pressing need for research 
on optimal remedies.

Apoptosis is a common pathway for TKI targeted therapy and it is regulated by p53, bcl-2, fas, ICE, mdr, and other apoptosis-related genes [9-11]. Abnormal expression of these genes can lead to TKI resistance. Regulating apoptosis-related genes and their expression products can reverse TKI resistance [12]. The sensitivity of cell apoptosis is mainly regulated by bcl- 2 and $\mathrm{p} 53$ genes. The $\mathrm{p} 53$ protein is a factor that induces apoptosis after DNA damage and mediates cell cycle arrest by up-regulating the p21 protein. Cell cycle arrest can save time for DNA repair. On the other hand, if the intracellular damage cannot be repaired, the p53 protein promotes cell apoptosis [13]. The bcl-2 gene, a member of the bcl-2 family, can block cell apoptosis without affecting cell proliferation while some members of the bcl-2 family, such as the Bax gene, can promote apoptosis. Most cancer cells have lost or no function of the p53 gene, meanwhile some cancer cells produce excessive bcl-2 protein, thus inhibiting the apoptosis of cancer cells $[14,15]$.

$\beta$-elemene, a bioactive compound extracted from Curcuma aromatica Salisb. (Curcuma wenyujin Y.H. Chen \& C.Ling) [16,17], has been widely used as an antitumor agent to treat a variety of tumors including lung cancer, liver cancer, digestive tract cancer, and bladder cancer, etc., even the patients with TKIresistant NSCLC can also benefit from the concurrent use of $\beta$-elemene with TKIs [18-21], however, the effects of $\beta$-elemene on TKI-resistant lung cancer and the underlying mechanisms of action are largely unknown. To address these issues, we investigated the effects of $\beta$-elemene on EGFR L858R/ T790M double mutation NCI-H1975 cells and the potential molecular mechanisms.

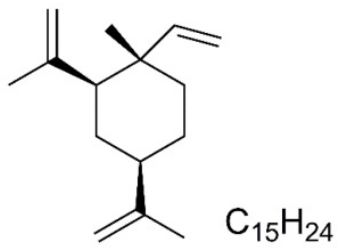

Figure 1. The chemical structure of $\beta$-elemene.

\section{Materials and methods}

\section{Reagents and instruments}

$\beta$-elemene was purchased from LKT Labs Co., Ltd (St. Paul, MN, USA). Erlotinib was obtained from Sigma Co., Ltd (St. Louis, MO, USA). Primary antibodies against p-mTOR (Ser2448), p-EGFR (Tyr1068), p-AMPKa (Thr172), p-Erk1/2 (Thr202/Tyr204), p-AKT (Ser473), t-mTOR, t-EGFR,
t-Erk, GAPDH, t-AKT, Bax, CHOP, and PARP were purchased from Cell Signaling Technology (Danvers, MA, USA). Annexin V/PI staining dye was purchased from BD Biosciences (San Jose, CA, USA). Equipment used in this study included flow cytometry (BD Biosciences, USA), spectraMax paradigm multimode microplate reader (Molecular Devices, CA, USA), electrophoresis and transfer film equipment (Bio-Rad, Hercules, CA, USA), and high-speed centrifuge (Eppendorf, Hamburg, Germany). $\beta$-elemene and erlotinib were dissolved in dimethyl sulfoxide (DMSO) to various working concentrations when used.

\section{Cell lines and cell culture}

The human NSCLC NCI-H1975 cell line, purchased from the American Type Culture Collection (ATCC, Manassas, VA, USA), has EGFR L858R/T790M double mutations and is resistant to erlotinib. NCI-H1975 cells were grown in monolayer culture in RPMI-1640 medium supplemented with $10 \%$ fetal bovine serum (FBS), $100 \mu \mathrm{g} / \mathrm{mL}$ streptomycin, $100 \mathrm{U} / \mathrm{mL}$ penicillin and were cultured at $37{ }^{\circ} \mathrm{C}$ in a humidified atmosphere containing $5 \%$ $\mathrm{CO}_{2}$. Exponentially growing cells were used in all experiments.

\section{Colony formation assay}

NCI-H1975 cells were planted into six-well plates (1,000 cells/well), respectively. After attachment overnight, the cells were treated with various concentrations of $\beta$-elemene $(0,20,40,60$, and $80 \mu \mathrm{g} / \mathrm{mL}$ ), and the medium was replaced every 4 days. The medium was discarded when colony formation was observed. The colonies were gently washed with ice-cold PBS, fixed in $4 \%$ paraformaldehyde (PFA) for $15 \mathrm{~min}$, and stained with $0.5 \%$ crystal violet (containing $0.5 \%$ crystal violet, $20 \%$ methanol, and 1\% PFA in $\mathrm{ddH}_{2} \mathrm{O}$ ) for $30 \mathrm{~min}$. After the excessive crystal violet solution was removed, the colonies formed were photographed and analyzed.

\section{Scratch wound healing assay}

NCI-H1975 cells were planted into six-well plates $\left(5 \times 10^{5}\right.$ cells/well) and incubated overnight. When the cells were approximately $70 \%$ confluent, the confluent monolayer was scratched with the tip of a $200 \mathrm{~mL}$ sterile pipette. The detached cells were gently washed twice with medium and removed. The cells were treated with various concentrations of $\beta$-elemene $(0,10,20,30,40$, and $50 \mu \mathrm{g} / \mathrm{mL})$. After additional 24 hours of growth, the cells were washed twice with PBS, and images of cell monolayers were taken with a microscope using the same configurations. 


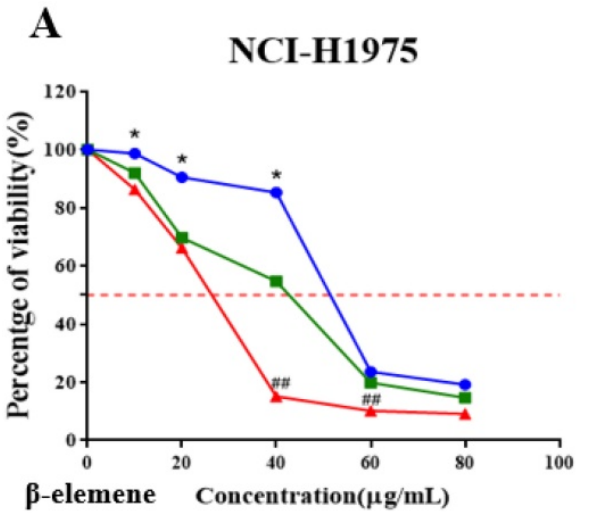

B

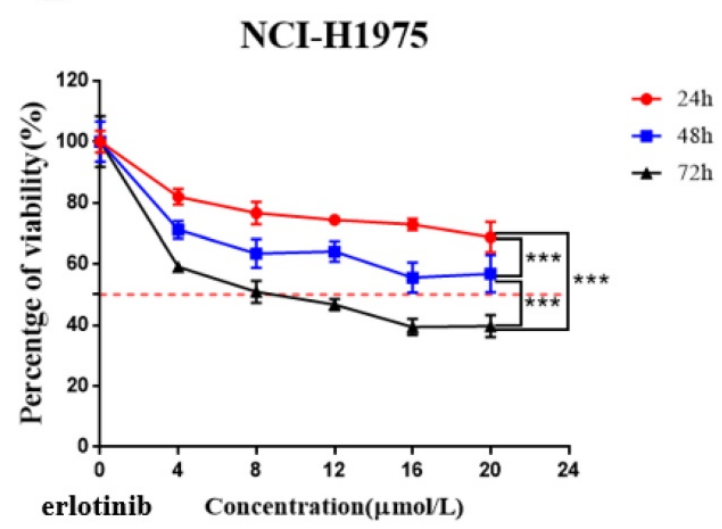

C

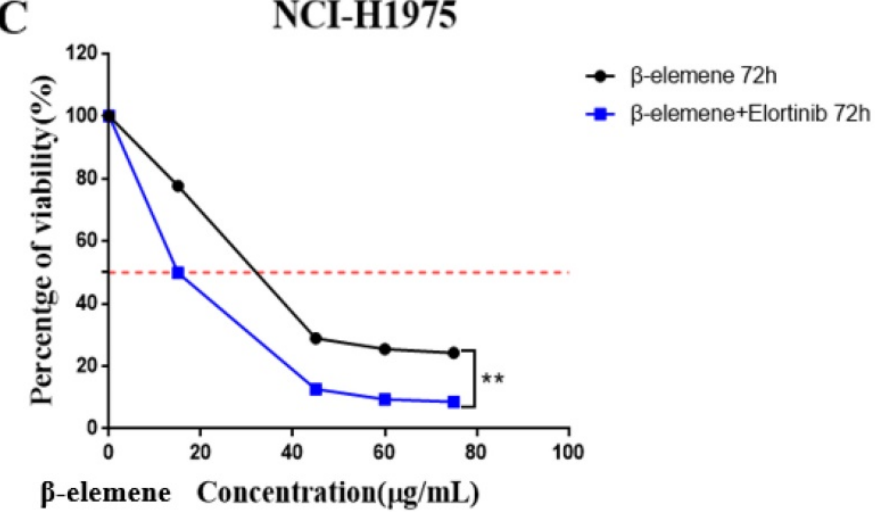

D

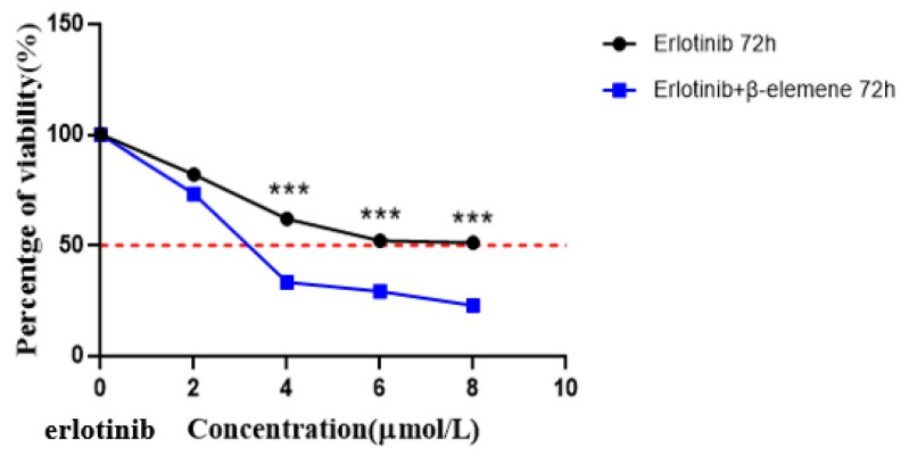

Figure 2. (A) Time- and dose-dependent growth inhibitory effects of $\beta$-elemene on $\mathrm{NCl}-\mathrm{H} 1975$ cells. The cells were incubated with $\beta$-elemene for 24,48 , and 72 hrs, and the cell viability was determined by MTT assay. Data are representative of at least three independent experiments and expressed as mean \pm SD; $* p<0.05$, ** $p<0.01$, versus the cells treated for 48 hrs or 72 hrs; $\# p<0.05$, ${ }^{\prime} p<0.01$, versus the cells treated for 48 hrs. (B) Time- and dose-dependent growth inhibitory effects of erlotinib on NCl-H1975 cells. The cells were incubated with $\beta$-elemene for 24,48 , and $72 \mathrm{hrs}$, and the cell viability was determined by MTT assay. Data are representative of at least three independent experiments and expressed as mean $\pm S D ; * p<0.05$, **p $<0.01$, ***p $<0.001$. (C) Compared with $\beta$-elemene alone, erlotinib combined with $\beta$-elemene significantly inhibited the growth of $\mathrm{NCl}-\mathrm{H} 1975$ cells. The cells were incubated with indicated concentrations of $\beta$-elemene with or without $2 \mu \mathrm{mol} / \mathrm{L}$ erlotinib for 72 hrs, and the cell viability was determined by MTT assay. Data are representative of at least three independent experiments and expressed as mean \pm SD; $* p<0.05$, **p $<0.01$, erlotinib plus $\beta$-elemene versus $\beta$-elemene alone. (D) $\beta$-elemene significantly increased the sensitivity of $\mathrm{NCl}-\mathrm{H} 1975$ cells to erlotinib. The cells were incubated with indicated concentrations of erlotinib with or without $30 \mu \mathrm{g} / \mathrm{mL} \beta$-elemene for $72 \mathrm{hrs}$, and the cell viability was determined by MTT assay. Data are representative of at least three independent experiments and expressed as mean $\pm S D ; *_{p}<0.05,{ }^{* *} p<0.01,{ }^{* * *} p<0.001$, erlotinib plus $\beta$-elemene versus erlotinib alone.

\section{MTT cytotoxicity assay}

NCI-H1975 cells were seeded on a 96-well microplate (5000 cells/well) and cultured overnight for cell adhesion. Two experiments were synchronously carried out to determine the sensitivity of NCI-H1975 cells to $\beta$-elemene or erlotinib, the cells were treated with a range of concentrations of $\beta$-elemene $(0,10,20,40,60$, and $80 \mu \mathrm{g} / \mathrm{mL}$ ) (Fig. $2 \mathrm{~A}$ ), or erlotinib $(0,4,8,12,16$, and $20 \mu \mathrm{mol} / \mathrm{L}$ ) (Fig. 2B) respectively for $24 \mathrm{hrs}, 48 \mathrm{hrs}$, and $72 \mathrm{hrs}$, and the cell viability was assessed by 3-(4,5-dimethylthiazol-2-yl)2,5-diphenyltetrazolium bromide (MTT) assay.

Then we carried out two experiments to investigate the synergistic effect of the combined use of $\beta$-elemene and erlotinib on NCI-H1975 cells: (a) The cells in the experiment group were treated with erlotinib $(2 \mu \mathrm{mol} / \mathrm{L})$ plus a range of concentrations of $\beta$-elemene $(0,15,45,60$, and $75 \mu \mathrm{g} / \mathrm{mL})$ for $72 \mathrm{hrs}$, and the control group was only treated with the same concentrations of $\beta$-elemene (Fig. 2C); (b) The cells in the experiment group were treated with a range of concentrations of erlotinib $(0,2,4,6$ and $8 \mu \mathrm{mol} / \mathrm{L})$ combined with $\beta$-elemene $(30 \mu \mathrm{g} / \mathrm{mL})$ for $72 \mathrm{hrs}$, while the control group was only treated with the same concentrations of erlotinib (Fig. 2D).

In all the above experiments, the cell viability was evaluated using a standard MTT assay. Twenty $\mu \mathrm{L}$ of MTT $(5 \mathrm{mg} / \mathrm{mL})$ solution was added to each well and incubated for $4 \mathrm{hrs}$, then culture medium was discarded and $150 \mu \mathrm{L}$ of DMSO per well was added with oscillation for $10 \mathrm{~min}$ to dissolve the formazan crystals. Each dose was repeated in triplicate. Finally, we used a Tecan microplate reader (Tecan US, Inc., Morrisville, NC, USA) to measure the colorimetric intensity of the plates with a test wavelength at $570 \mathrm{~nm}$ and a reference wavelength at $650 \mathrm{~nm}$, and calculated the cell viability as the percent change in absorbance of the treated cells divided by the absorbance of the untreated ones. 


\section{Apoptosis assay}

The NCI-H1975 cell line was seeded on a 6-well plate $\left(2 \times 10^{5}\right.$ cells $)$ and were serum-starved overnight. Cells were treated with erlotinib $(2 \mu \mathrm{mol} / \mathrm{L})$ and different concentrations of $\beta$-elemene for 24 hours. The treated cells were centrifuged after trypsin digestion. For the analysis of cell apoptosis, the cells were washed twice with cold PBS, stained with $5 \mu \mathrm{L}$ Annexin $\mathrm{V}$ fluorescein and $5 \mu \mathrm{L}$ propidium iodide (PI, $1 \mathrm{mg} / \mathrm{mL}$ ) for 15 minutes at room temperature in the dark, and were then suspended in $400 \mu \mathrm{L}$ of Annexin $\mathrm{V}$ binding buffer (BD Biosciences). BD FACSAria III (BD Biosciences, USA) was used to quantitatively determine the percentage of apoptotic cells.

\section{Western blot analysis}

Protein samples were prepared from whole cell lysates and western blot was performed as follows. The cells were lysed in RIPA buffer $(150 \mathrm{mmol} / \mathrm{L}$ $\mathrm{NaCl}, 50 \mathrm{mmol} / \mathrm{L}$ Tris- $\mathrm{HCl} \mathrm{pH}$ 8.0, 1\% Triton X-100, $1 \%$ deoxycholate, and $0.1 \%$ SDS) with protease inhibitor Roche and placed on ice for 10 minutes. The concentration of total protein extract was determined by Bio-Rad DCTM protein assay kit (Bio-Rad Laboratories, Bio-Rad Laboratories, Philadelphia, PA, USA). The same amount of total protein $(40 \mu \mathrm{g})$ was suspended in the loading buffer, boiled at $100^{\circ} \mathrm{C}$ for 5 minutes, separated by $10 \%$ SDS-PAGE, and transferred onto the nitrocellulose filter (NC) membranes (Millipore, Billerica, MA, USA). The membrane was blocked by $5 \%$ milk with Tween- 20 in Tris-buffered saline (TBS) at $4{ }^{\circ} \mathrm{C}$, and all kinds of primary antibodies were used overnight at $4{ }^{\circ} \mathrm{C}$. The following primary antibodies were utilized: rabbit polyclonal antibodies against GAPDH $(1: 1,000)$, phosphatase and mTOR, phosphatase and EGFR, phosphatase and Erk, phosphatase and AMPKa, Bax, poly (ADP-ribose) polymerase (PARP) $(1: 1,000)$, and phosphatase AKT (1: 2,000), mouse monoclonal antibody against $\mathrm{CHOP}(1: 1,000)$. The primary antibodies were incubated overnight at $4{ }^{\circ} \mathrm{C}$. Secondary HRP linked antibody (CST, MA, USA) was added to the membrane at 1:1000 dilution and incubated for 2 hours at room temperature after washing the membrane with TBST wash buffer three times (10 minutes/time). GAPDH was used as an internal reference protein for comparison and normalization. Immobilon western developer (Millipore, Merck KGaA, Darmstadt, Germany) and Amersham Imager 600 (General Electric, USA) were used to detect the signal intensity of the membranes.

\section{Statistical analysis}

All data were represented as mean \pm SD for three independent experiments. The inter-group differences were determined by one-way ANOVA, and then all paired chromatographic columns were compared by the Bonferroni's test. If $p<0.05$, the results were considered to be statistically significant.

\section{Results}

\section{Determination of the sensitivity of $\mathrm{NCl}-\mathrm{H} 1975$ cells to $\boldsymbol{\beta}$-elemene or erlotinib}

NCI-H1975 cells were exposed to a concentration gradient of $\beta$-elemene for $24 \mathrm{hrs}, 48 \mathrm{hrs}$, and $72 \mathrm{hrs,}$ and cell viability was assessed by MTT assay. The results clearly demonstrated that $\beta$-elemene doseand time-dependently inhibited the cell viability. (Fig. 2A).

NCI-H1975 cells were treated with 0, 4, 8, 12,16, and $20 \mu \mathrm{mol} / \mathrm{L}$ of erlotinib for 24,48 , and $72 \mathrm{hrs}$, as shown in Fig. 2B, erlotinib inhibited the growth of NCI-H1975 cells in a time- and dose-dependent manner, but $\mathrm{IC}_{50}$ of erlotinib was extremely high: 214.5 $\pm 2.32 \mu \mathrm{mol} / \mathrm{L}(48 \mathrm{hrs}$ ) and 9.971 $\pm 0.98 \mu \mathrm{mol} / \mathrm{L}$ (72 hrs).

\section{$\beta$-elemene enhances the antitumor activity of erlotinib on TKI-resistant $\mathrm{NCI}-\mathrm{H} 1975$ lung cancer cells}

NCI-H1975 lung cancer cells were exposed to a range of doses of $\beta$-elemene in the absence or presence of $2 \mu \mathrm{mol} / \mathrm{L}$ erlotinib for $72 \mathrm{hrs}$, the results showed that compared with $\beta$-elemene alone, erlotinib combined with $\beta$-elemene significantly inhibited the growth of NCI-H1975 cells ( $p<0.01$ ) (Fig. 2C). After being exposed to a range of doses of erlotinib in the absence or presence of $30 \mu \mathrm{g} / \mathrm{mL} \beta$-elemene, the $\beta$-elemene-treated cells showed significantly increased sensitivity to erlotinib $(p<0.001)$ (Fig. 2D). As shown in Fig. $2 \mathrm{C}$, the $\mathrm{IC}_{50}$ value of $\beta$-elemene in the experimental group $(14.85 \pm 1.13 \mu \mathrm{g} / \mathrm{mL})$ was significantly lower than that of the $\beta$-elemene group $(25.85 \pm 1.33 \mu \mathrm{g} / \mathrm{mL})(p<0.01)$, and as shown in Fig. $2 \mathrm{D}$, the $\mathrm{IC}_{50}$ value of erlotinib in the experimental group $(3.268 \pm 1.43 \mu \mathrm{mol} / \mathrm{L})$ was significantly lower than that of the control group (treated with erlotinib alone) $(9.765 \pm 1.13 \mu \mathrm{mol} / \mathrm{L})(p<0.001)$. These results suggested that $\beta$-elemene combined with erlotinib showed a synergistic inhibitory effect on NCI-H1975 cells, $\beta$-elemene could enhance the sensitivity of NCI-H1975 cells to erlotinib.

\section{$\beta$-elemene inhibits cell colony formation and wound healing ability in $\mathrm{NCI}-\mathrm{H} 1975$ cells}

Long-term colony formation assays of NCI-H1975 cells verified the growth-inhibiting effect of $\beta$-elemene. $\beta$-elemene significantly suppressed the colony formation capacities (Fig. 3) and wound 
healing ability (Fig. 4) of the NCI-H1975 cells in a dose-dependent manner.

\section{$\beta$-elemene inhibits the MAPK signaling pathway and activates the AMPK signaling pathway}

It was reported that MAPK and AMPK were upregulated in some types of cancer, such as breast and lung cancers, and might play a key role in the modulation of cell proliferation and survival. Therefore, we investigated whether $\beta$-elemene could inhibit the MAPK signaling pathway in our cell lines by determining the phosphorylation levels of the proteins involved in this pathway, such as Erk, mTOR, and EGFR. After treatment of the cells with $\beta$-elemene for $24 \mathrm{hrs}$, we determined the phosphorylation levels of these key proteins involved in this pathway. As shown in Fig. 5, western blot results showed that $\beta$-elemene reduced the levels of phosphorylation of mTOR, EGFR, and Erk in a dose-dependent manner and activating the AMPK in NCI-H1975 cell lines, suggesting an involvement of the MAPK pathway.

\section{Combination use of $\beta$-elemene and erlotinib synergistically enhances the apoptosis in erlotinib-resistant $\mathrm{NCl}-\mathrm{H1} 975$ cells}

To investigate the anti-cancer properties of $\beta$-elemene, we determined the level of cell apoptosis by flow cytometry using AnnexinV-FITC/propidium iodide (PI) staining. The results are shown in Fig. 6 . $\beta$-elemene induced limited apoptosis in NCI-H1975 cells in low dosage, and the cells experienced extensive apoptosis with increased treatment dosage. To examine whether the increased sensitivity to erlotinib conferred by $\beta$-elemene is related to increased levels of apoptosis, we performed western blot analysis and flow cytometry following double-staining with annexin V-FITC and PI, which suggests typical changes of apoptosis. As shown in Fig. 6 and Fig. 7, western blot results showed that $\beta$-elemene inhibited the expression of CHOP, PARP while it activated Bax. The cell apoptosis rate was analyzed by flow cytometry (Fig. 6), the overall rate of apoptosis $(\mathrm{Q} 2+\mathrm{Q} 3)$ in the erlotinib-only group was only $5.91 \%$, indicating that treatment with $2 \mu \mathrm{mol} / \mathrm{L}$ erlotinib alone failed to induce NCI-H1975 cell apoptosis, but when treated with erlotinib plus $\beta$-elemene, the overall apoptosis rate increased from $5.91 \%$ to $37.48 \%$. $\beta$-elemene plus erlotinib evidently induced NCI-H1975 apoptosis, the early apoptotic rate was $5.26 \%-7.38 \%$, and the middle-late apoptotic rate was $12.7 \%-30.1 \%$. These results indicated that $\beta$-elemene combined with erlotinib promoted apoptosis of NCI-H1975 cells.

\section{Discussion}

The EGFR-mediated signaling pathways are essential for various biological processes including cancer development and progression, such as cell proliferation, adhesion, migration, differentiation, etc. [22-24], therefore, the EGFR tyrosine kinase has become an attractive target in cancer therapy, especially for NSCLC treatment. Since the first-generation EGFRTKIs such as gefitinib and erlotinib were approved for the treatment of NSCLC in the early 2000s [25,26], TKIs have achieved some clinical benefits in the treatment of NSCLC with common EGFR activating mutations such as L858R and del E746-A750 $[27,28]$ Unfortunately, acquired resistance to TKIs is usually inevitable in almost all patients. A secondary T790M point mutation at the gatekeeper position of EGFR causes approximately $60 \%$ of NSCLC patients to develop
Figure 4. Colony formation of $\mathrm{NCl}-\mathrm{H} 1975$ cells treated with $\beta$-elemene $(0,20,40,60$, and $80 \mu \mathrm{g} / \mathrm{mL})$ and monitored for 14 days. Representative photomicrographs of crystal violet-stained colonies were depicted. 
acquired resistance after TKI treatment for a median of 10-14 months. Among the patients who have a double and coexisting mutation profile, double mutations L858R and T790M possess the highest

$\mathbf{A}$

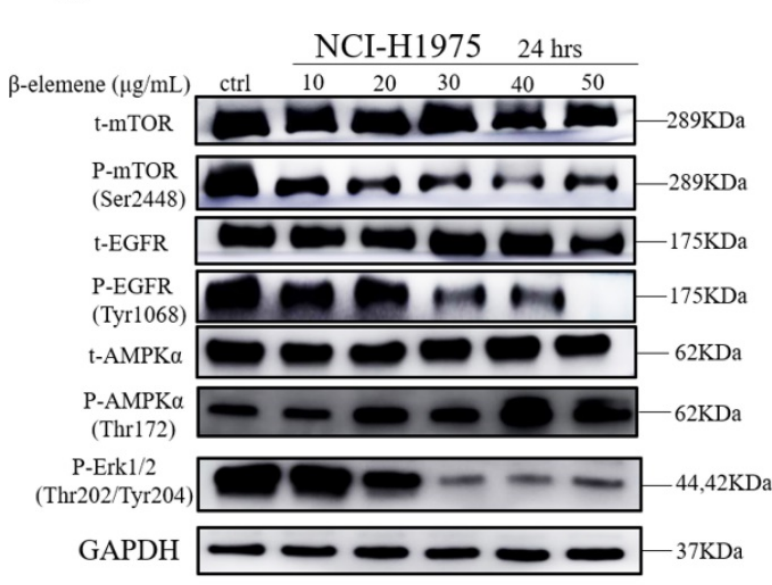

B incidence rate (9.8\%) [29] and lead to the poor treatment outcome of NSCLC victims [32-35], optimal treatment strategies are desperately needed for the specific subsets of patients [36-40].
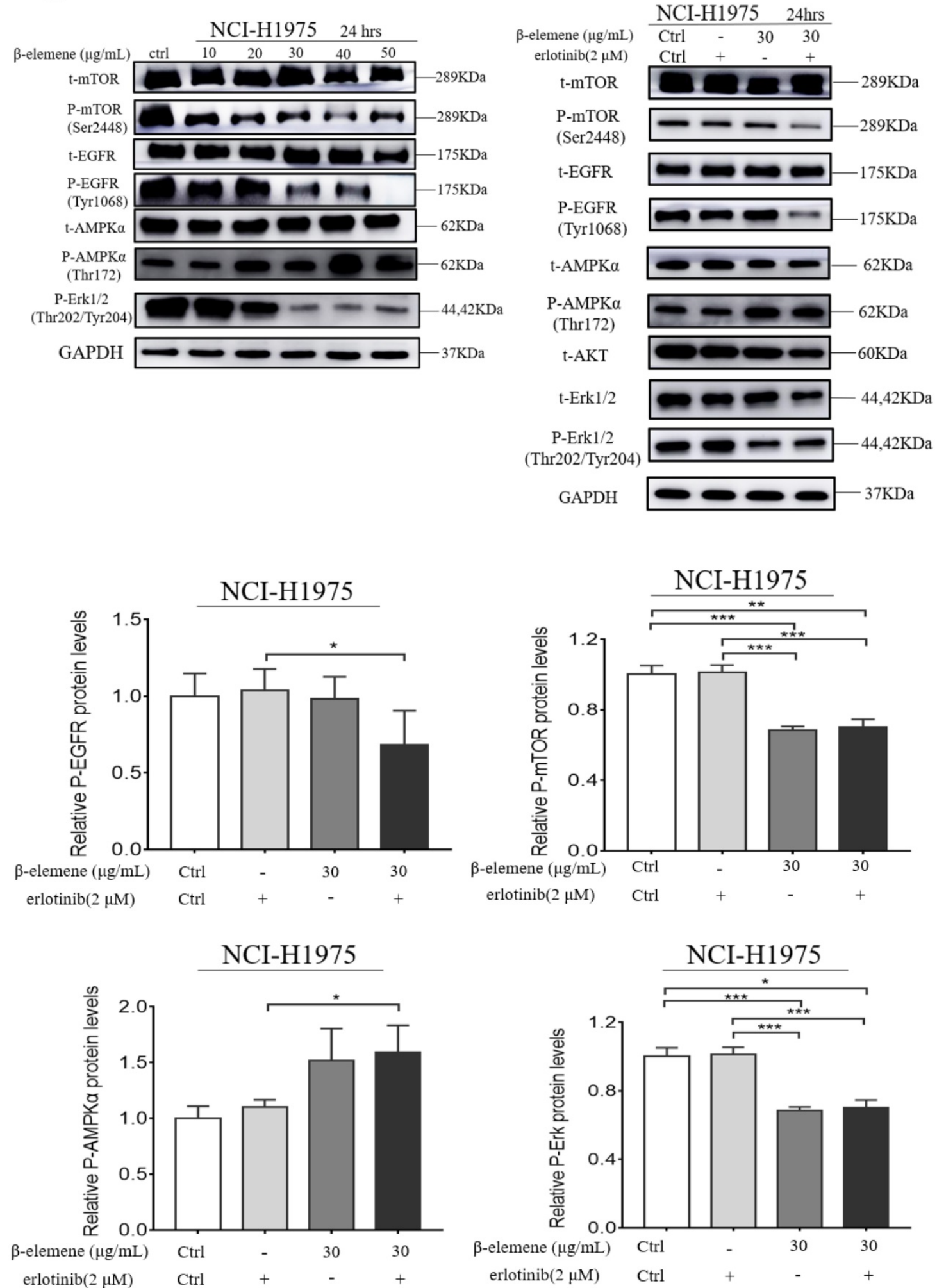

Figure 5. (A) $\mathrm{NCl}-\mathrm{H} 1975$ cells were treated with $\beta$-elemene $(0,10,20,30,40,50 \mu \mathrm{g} / \mathrm{mL})$ for $24 \mathrm{hrs}$. (B) $\mathrm{NCl}-\mathrm{H} 1975 \mathrm{cells}$ were treated with $\beta$-elemene $(30 \mu \mathrm{g} / \mathrm{mL})$ and/or Erlotinib $(2 \mu \mathrm{mol} / \mathrm{L})$ for $24 \mathrm{hrs}$. The expression of proteins was detected by western blot. Each experiment was repeated at least three times. Results are expressed as mean \pm SD $(\mathrm{n}=3, * p<0.05$, ** $p<0.01, * * * p<0.001)$. 


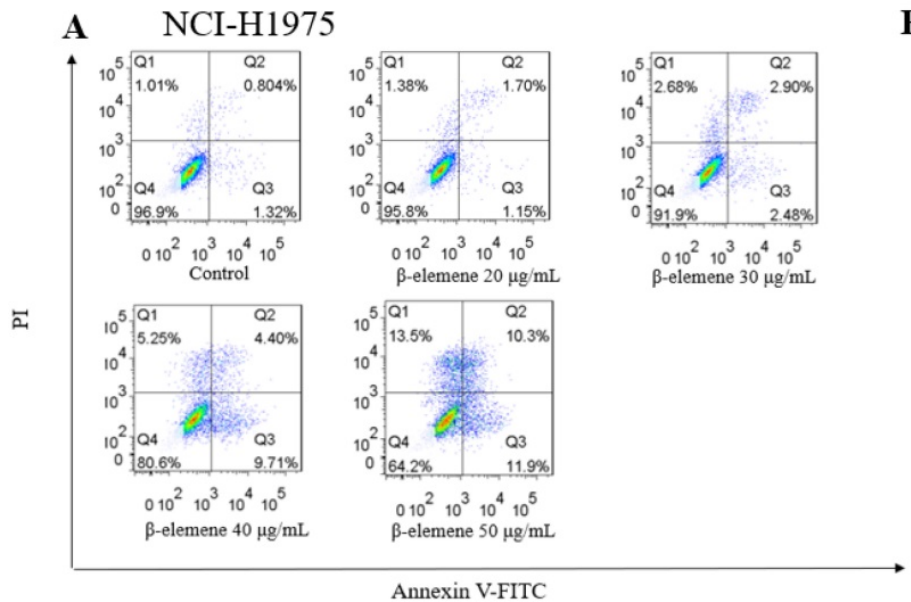

B

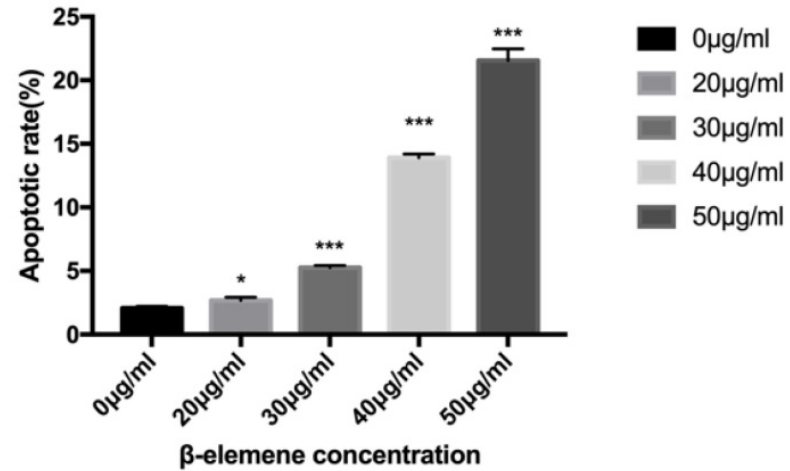

C

\section{NCI-H1975}

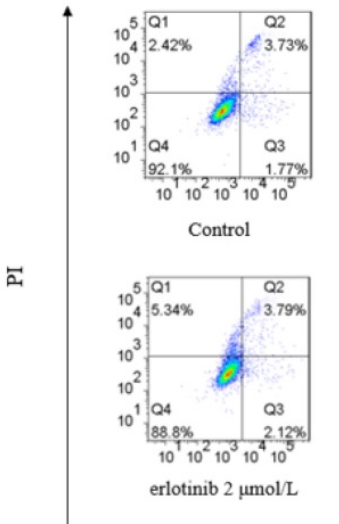

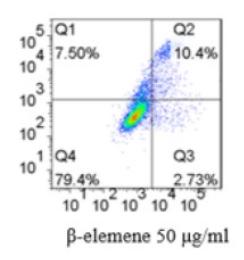

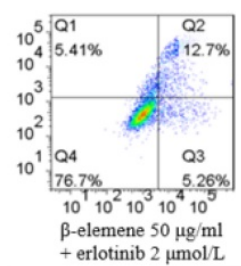

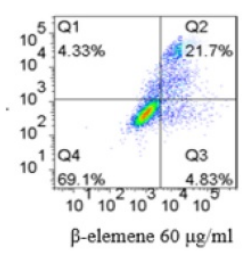

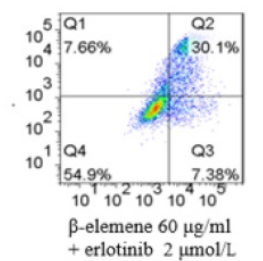

D

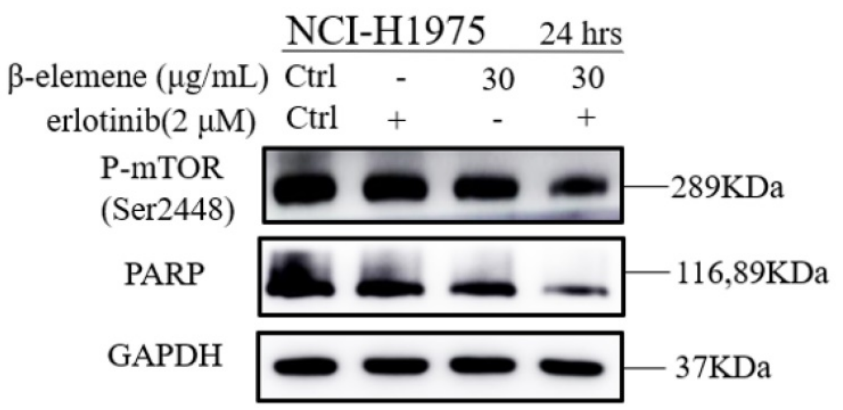

Figure 6. (A) $\mathrm{NCl}-\mathrm{H} 1975$ cells were treated with $\beta$-elemene at different concentrations $(0,20,30,40$, and $50 \mu \mathrm{g} / \mathrm{mL})$ for $24 \mathrm{hrs}$. Cell apoptosis was measured by flow cytometry using Annexin V-FITC/PI staining. (B) Statistical analysis of the cell apoptosis rate at $24 \mathrm{hrs}$. All data are presented as mean \pm SD $(n=3, * p<0.05$, $* * p<0.01$, $* * * p<0.001)$. (C) Annexin V-FITC/ PI staining and flow cytometry analysis of the effect of $\beta$-elemene on apoptosis of $\mathrm{NCl}-\mathrm{H} 1975$ cells. (D)NCl-H1975 cells were treated with $\beta$-elemene (30 $\mu \mathrm{g} / \mathrm{mL})$ and/or erlotinib $(2 \mu \mathrm{mol} / \mathrm{L})$ for $24 \mathrm{hrs}$. The expression of proteins was detected by Western blot. FITC, fluorescein isothiocyanate; PI, propidium iodide.

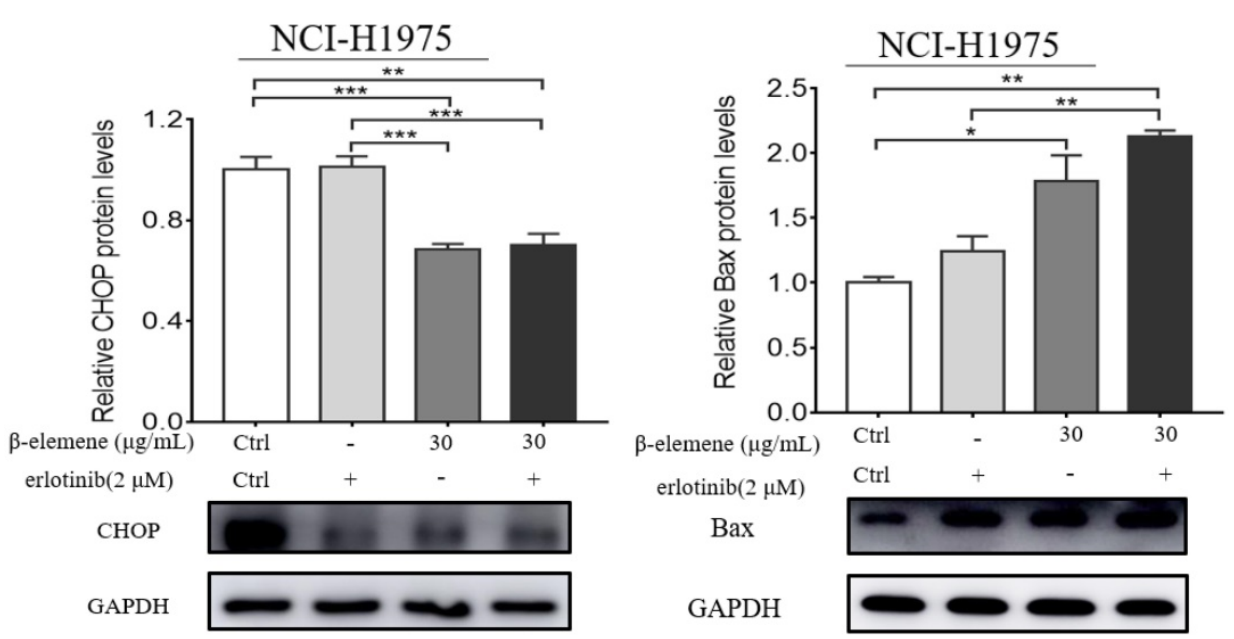

Figure 7. $\mathrm{NCl}-\mathrm{H} 1975$ cells were treated with $\beta$-elemene $(30 \mu \mathrm{g} / \mathrm{mL})$ and/or Erlotinib $(2 \mu \mathrm{mol} / \mathrm{L})$ for 24 hrs. The expression of $\mathrm{CHOP}$ and Bax were detected by Western blot. Each experiment was repeated at least three times. Results are expressed as mean $\pm \operatorname{SD}(n=3, * p<0.05, * * p<0.01, * * * p<0.001)$.

In China, Chinese medicines and their active ingredients have been widely used to treat lung cancer including TKI-resistant NSCLC[18,41-45], and some of them have shown a synergistic inhibitory effect and lower TKIs resistance in EGFR L858R+T790M-Mutated H1975 Cells [18,32-35]. 
$\beta$-elemene is one of these bioactive compounds and has been used to treat various cancers and has shown satisfactory efficacy with mild adverse effects [46-48]. Some studies have shown that $\beta$-elemene can reverse drug resistance of cancer cells, enhance the sensitivity of cancer cells to chemotherapeutic drugs [46-48]. It can induce apoptosis in lung cancer cells and other types of solid tumor cells [46-48], but the effects of $\beta$-elemene and its mechanisms of action against TKI-resistant L858R/T790M mutated NSCLC remain unknown.

The NCI-H1975 cell line harboring the mutations L858R and T790M [30,31] was selected for our study and treated with varying concentrations of $\beta$-elemene and/or erlotinib. The combined effects of $\beta$-elemene and erlotinib were evaluated. The results showed that $\beta$-elemene combined with erlotinib had a synergistic inhibitory effect on NCI-H1975 cells. $\beta$-elemene significantly inhibited the growth, colony formation capacity, and wound healing ability of NCI-H1975 cells, and improved the sensitivity of NCI-H1975 cells to erlotinib. Our results indicated that $\beta$-elemene might be a potential adjunctive treatment to TKI treatment for TKI-resistant NSCLC with the mutations L858R and T790M.

The MAPK pathway has been regarded as a crucial drug target for the treatment of cancer, including NSCLC [49]. MAPKs family members play a key role in cell proliferation and apoptosis regulation [50]. The Akt/mTOR is another important signaling pathway in regulating cell proliferation and apoptosis [51,52]. mTOR has been regarded as an important target for the treatment of NSCLC. In our study, we found that $\beta$-elemene plus erlotinib had a synergistic effect on the proliferation and apoptosis of NCI-H1975 cells. $\beta$-elemene exerted potent reversal effects on TKI-resistant NCI-H1975 cell line in vitro through down-regulation of p-mTOR, p-EGFR, p-Erk, $\mathrm{CHOP}$ expression, and the activation of p-AMPKa and Bax, thus increasing the sensitivity of NCI-H1975 cells to erlotinib. These findings indicated that cell apoptosis induction contributed to the $\beta$-elemenemediated inhibition of NCI-H1975 cell proliferation, indicating that $\beta$-elemene might help to overcome TKI resistance and improve the treatment outcome of these NSCLC patients.

However, the present study has some limitations: (a) This study is a preliminary in vitro study, all data are from in vitro experiments, which do not always extrapolate to the in vivo setting, more studies, especially animal experiments, are still needed to further confirm our findings. (b) The present study only studied the synergistic effect of $\beta$-elemene on the antitumor activity of erlotinib in TKI-resistant H1975 lung cancer cells and did not compare the difference in the effects of $\beta$-elemene between TKI-resistant and TKI-sensitive lung cancer cells. In the future, we will further investigate the effect of $\beta$-elemene on the TKI-sensitive lung cancer cells, such as HCC827 cells.

\section{Conclusion}

In summary, our data provide evidence that $\beta$-elemene can inhibit the proliferation and migration of NCI-H1975 cells by inducing apoptosis. The anti-tumor effect is associated with the inhibition of MAPK activity and activation of AMPKa activity. $\beta$-elemene improves the sensitivity of NCI$\mathrm{H} 1975$ cells to erlotinib, indicating that $\beta$-elemene is a promising anti-cancer therapeutic candidate for TKI-resistant NSCLC. Inhibition of apoptosis might be one of the mechanisms of the anti-tumor effects of $\beta$-elemene against NCI-H1975 cells.

\section{Acknowledgements}

This study was funded by the Science and Technology Development Fund, Macau SAR (File No.: 130/2017/A3, 0099/2018/A3, 0052/2018/A2 and 0096/2018/A3), the National Natural Science Foundation of China (Grant No. 81874380, 81672932 and 81730108), National Nature Science Foundation of China(Grant No. 82004346), Science and Technology Planning Project of Guangdong Province (2020B1212030008), the Zhejiang Provincial Natural Science Foundation of China for Distinguished Young Scholars (Grant No. LR18H160001), the Zhejiang province science and technology project of TCM (Grant No. 2019ZZ016) and the Key Project of Hangzhou Ministry of Science and Technology (Grant No. 20162013A07, 20142013A63).

\section{Author contributions}

XB Sui, EL Leung, and QB Wu conceived this research, led the project, and revised the manuscript. J Wang, C Xu, Y Chen, L Shao, T Li, XX Fan, and LL Yu carried out the cell culture studies, molecular biology experiments, data collection, statistical analysis. RN Zhang, B Chen, and HW Chen participated in the molecular biology experiments. J Wang and $\mathrm{C} \mathrm{Xu}$ wrote the manuscript. All authors reviewed the manuscript.

\section{Competing Interests}

The authors have declared that no competing interest exists.

\section{References}

1. Chen W, Zheng R, Baade PD, Zhang S, Zeng H, Bray F, et al. Cancer statistics in China, 2015. CA: a cancer journal for clinicians. 2016; 66: 115-32. 
2. Cicènas S, Žalienè A, Atkočius V. Treatment outcome of locally advanced stage IIIA/B lung cancer. Medicina. 2009; 45: 452-9.

3. Wu X, Wu Q, Zhou X, Huang J. SphK1 functions downstream of IGF-1 to modulate IGF-1-induced EMT, migration and paclitaxel resistance of A549 cells: A preliminary in vitro study. Journal of Cancer. 2019; 10: 4264-4269.

4. Wu Q, Yao X, Chen H, Liu Z, Li T, Fan X, et al. Long-term aspirin use for primary cancer prevention: An updated systematic review and subgroup meta-analysis of 29 randomized clinical trials. Journal of Cancer. 2020; 11: 6460-6473.

5. Xu C, Yao X, Li T, Wang J, An B, Wang J, et al. Pretreatment neutrophil-to-lymphocyte ratio is a predictive biomarker for EGFR TKI-treated patients with advanced EGFR-mutant Non-small cell lung cancer. Translational Cancer Research. 2020; 9: 2875-83.

6. Szkorupa M, Klein J, Bohanes T, Neoral C, Kolek V, Grygárková I. Neoadjuvant chemotherapy and surgical treatment in advanced stages of non-small cell lung cancer. Rozhledy $\mathrm{v}$ chirurgii: mesicnik Ceskoslovenske chirurgicke spolecnosti. 2011; 90: 433-9.

7. Spásová I. The position of neoadjuvant chemotherapy in the treatment of non-small-cell lung carcinoma. Vnitrni lekarstvi. 2007; 53: 715-23.

8. Goldberg SB, Oxnard GR, Digumarthy S, Muzikansky A, Jackman DM, Lennes IT, et al. Chemotherapy with erlotinib or chemotherapy alone in advanced non-small cell lung cancer with acquired resistance to EGFR tyrosine kinase inhibitors. The oncologist. 2013; 18: 1214-20.

9. Chan KT, Lung ML. Mutant p53 expression enhances drug resistance in a hepatocellular carcinoma cell line. Cancer chemotherapy and pharmacology. 2004; 53: 519-26.

10. Bainer RO, Trendowski MR, Cheng C, Pei D, Yang W, Paugh SW, et al. A p53-regulated apoptotic gene signature predicts treatment response and outcome in pediatric acute lymphoblastic leukemia. Cancer management and research. 2017; 9: 397-410.

11. Hu Y, Qin X, Cao H, Yu S, Feng J. Reversal effects of local anesthetics on P-glycoprotein-mediated cancer multidrug resistance. Anti-cancer drugs. 2017; 28: 243-9.

12. Liu Q, Yu S, Zhao W, Qin S, Chu Q, Wu K. EGFR-TKIs resistance via EGFR-independent signaling pathways. Molecular cancer. 2018; 17: 1-9.

13. Nakamura $Y$, Arakawa H. Discovery of Mieap-regulated mitochondrial quality control as a new function of tumor suppressor p53. Cancer science. 2017; 108: 809-17.

14. Efferth T, Gebhart E, Ross DD, Sauerbrey A. Identification of gene expression profiles predicting tumor cell response to L-alanosine. Biochemical pharmacology. 2003; 66: 613-21.

15. Gillet R, Grimber G, Cavard C, Bennoun M, Mignon A, Briand P, et al. Effect of Bcl-2 expression on hepatic preneoplasia in mice. Cancer letters. 2002; 177: 189-95

16. Ju J, Yu W, Fu C, Ma L. Modern research and clinical application of $\beta$-elemene. Qilu Pharmaceutical Affairs. 2008; 27: 546-8.

17. Guo HQ, Zhang GN, Wang YJ, Zhang YK, Sodani K, Talele TT, et al. $\beta$-Elemene, a compound derived from Rhizoma zedoariae, reverses multidrug resistance mediated by the ABCB1 transporter. Oncology reports. 2014; 31: 858-66.

18. Zhang R, Pan T, Xiang $\mathrm{Y}$, Zhang M, Feng J, Liu S, et al. $\beta$-Elemene Reverses the Resistance of p53-Deficient Colorectal Cancer Cells to 5-Fluorouracil by Inducing Pro-death Autophagy and Cyclin D3-Dependent Cycle Arrest. Frontiers in Bioengineering and Biotechnology. 2020; 8: 378 .

19. Zhai B, Wu Q, Wang W, Zhang M, Han X, Li Q, et al. Preparation, characterization, pharmacokinetics and anticancer effects of PEGylated $\beta$-elemene liposomes. Cancer biology \& medicine. 2020; 17: 60.

20. Chen B, Zhang RN, Fan X, Wang J, Xu C, An B, et al. Clinical diagnostic value of long non-coding RNAs in Colorectal Cancer: A systematic review and meta-analysis. Journal of Cancer. 2020; 11: 5518.

21. Wu Q, Leung ELH. Association of Dietary Fiber and Yogurt Consumption with Lung Cancer Risk. JAMA oncology. 2020; 6: 788.

22. Yarden $Y$, Sliwkowski MX. Untangling the ErbB signalling network. Nature reviews Molecular cell biology. 2001; 2: 127-37.

23. Oda K, Matsuoka Y, Funahashi A, Kitano H. A comprehensive pathway map of epidermal growth factor receptor signaling. Molecular systems biology. 2005; 1: 2005.0010.

24. Peters S, Zimmermann S, Adjei AA. Oral epidermal growth factor receptor tyrosine kinase inhibitors for the treatment of non-small cell lung cancer: comparative pharmacokinetics and drug-drug interactions. Cancer treatment reviews. 2014; 40: 917-26.

25. Cohen MH, Williams GA, Sridhara R, Chen G, McGuinn WD, Morse D, et al. United States Food and Drug Administration drug approval summary: gefitinib (ZD1839; Iressa) tablets. Clinical Cancer Research. 2004; 10: 1212-8.
26. Cohen MH, Johnson JR, Chen YF, Sridhara R, Pazdur R. FDA drug approval summary: erlotinib (Tarceva $\left.{ }^{\circledR}\right)$ tablets. The oncologist. 2005; 10: 461-6.

27. Cataldo VD, Gibbons DL, Pérez-Soler R, Quintás-Cardama A. Treatment of non-small-cell lung cancer with erlotinib or gefitinib. New England Journal of Medicine. 2011; 364: 947-55.

28. Mitsudomi T, Morita S, Yatabe Y, Negoro S, Okamoto I, Tsurutani J, et al. Gefitinib versus cisplatin plus docetaxel in patients with non-small-cell lung cancer harbouring mutations of the epidermal growth factor receptor (WJTOG3405): an open label, randomised phase 3 trial. The lancet oncology. 2010; 11: 121-8.

29. Li S, Li L, Zhu Y, Huang C, Qin Y, Liu H, et al. Coexistence of EGFR with KRAS, or BRAF, or PIK3CA somatic mutations in lung cancer: a comprehensive mutation profiling from 5125 Chinese cohorts. British journal of cancer. 2014; 110: 2812-20.

30. Mulshine JL, Johnson B. NCI-Navy Medical Oncology Branch Cell Line Supplement. 1996;24:1-291.

31. Sordella R, Bell DW, Haber DA, Settleman J. Gefitinib-sensitizing EGFR mutations in lung cancer activate anti-apoptotic pathways. Science. 2004; 305: 1163-7.

32. Chen Z, Tian D, Liao X, Zhang Y, Xiao J, Chen W, et al. Apigenin combined with gefitinib blocks autophagy flux and induces apoptotic cell death through inhibition of HIF-1a, c-Myc, p-EGFR, and glucose metabolism in EGFR L858R+T790M-mutated H1975 cells. Frontiers in pharmacology. 2019; 10: 260.

33. Li X, Fan XX, Jiang ZB, Loo WT, Yao XJ, Leung ELH, et al. Shikonin inhibits gefitinib-resistant non-small cell lung cancer by inhibiting TrxR and activating the EGFR proteasomal degradation pathway. Pharmacological Research. 2017; 115: 45-55.

34. Li S, Liu Z, Zhu F, Fan X, Wu X, Zhao H, et al. Curcumin lowers erlotinib resistance in non-small cell lung carcinoma cells with mutated EGF receptor. Oncology Research Featuring Preclinical and Clinical Cancer Therapeutics. 2014; 21: 137-44.

35. Xie YJ, Gao WN, Wu QB, Yao XJ, Jiang ZB, Wang YW, et al. Chelidonine selectively inhibits the growth of gefitinib-resistant non-small cell lung cancer cells through the EGFR-AMPK pathway. Pharmacological Research. 2020; 159: 104934

36. Wada K, Lee JY, Hung HY, Shi Q, Lin L, Zhao Y, et al. Novel curcumin analogs to overcome EGFR-TKI lung adenocarcinoma drug resistance and reduce EGFR-TKI-induced GI adverse effects. Bioorganic \& medicinal chemistry. 2015; 23: 1507-14.

37. Xu J, Wang Q, Leung ELH, Li Y, Fan X, Wu Q, et al. Compound C620-0696, a new potent inhibitor targeting BPTF, the chromatin-remodeling factor in non-small-cell lung cancer. Frontiers of medicine. 2020; 14: 60-7.

38. Chen P, Wu Q, Feng I, Yan L, Sun Y, Liu S, et al. Erianin, a novel dibenzyl compound in Dendrobium extract, inhibits lung cancer cell growth and migration via calcium/calmodulin-dependent ferroptosis. Signal transduction and targeted therapy. 2020; 5: 1-11.

39. Lin S, An X, Guo Y, Gu J, Xie T, Wu Q, et al. Meta-analysis of astragaluscontaining traditional Chinese medicine combined with chemotherapy for colorectal cancer: efficacy and safety to tumor response. Frontiers in oncology. 2019; 9: 749.

40. Chen H, Yao X, Li T, Lam CW-K, Zhang R, Zhang H, et al. Compound Kushen injection combined with platinum-based chemotherapy for stage III/IV non-small cell lung cancer: A meta-analysis of 37 RCTs following the PRISMA guidelines. Journal of Cancer. 2020; 11: 1883-1898.

41. Wang X, Liu Z, Sui X, Wu Q, Wang J, Xu C. Elemene injection as adjunctive treatment to platinum-based chemotherapy in patients with stage III/IV non-small cell lung cancer: a meta-analysis following the PRISMA guidelines. Phytomedicine. 2019; 59: 152787.

42. Chen W, Lu Y, Wu J, Gao M, Wang A, Xu B. Beta-elemene inhibits melanoma growth and metastasis via suppressing vascular endothelial growth factor-mediated angiogenesis. Cancer Chemotherapy and Pharmacology. 2011; 67: 799-808.

43. Li QQ, Wang G, Reed E, Huang L, Cuff CF. Evaluation of Cisplatin in Combination with $\beta$-Elemene as a Regimen for Prostate Cancer Chemotherapy. Basic \& clinical pharmacology \& toxicology. 2010; 107: 868-76.

44. Chen H, Yao X, Liu Z, Li T, Xu C, Wang J, et al. Efficacy and safety of Shenqi Fuzheng injection combined with platinum-based chemotherapy for stage III/IV non-small cell lung cancer: A protocol for systematic review and meta-analysis of randomized controlled trials. Medicine. 2019; 98.

45. Huang X, Wang J, Lin W, Zhang N, Du J, Long Z, et al. Kanglaite injection plus platinum-based chemotherapy for stage III/IV non-small cell lung cancer: a meta-analysis of 27 RCTs. Phytomedicine. 2020; 67: 153154 
46. Guo HQ, Zhang GN, Wang YJ, Zhang YK, Sodani K, Talele TT, et al. $\beta$-Elemene, a compound derived from Rhizoma zedoariae, reverses multidrug resistance mediated by the ABCB1 transporter. Oncology reports. 2014; 31: 858-66.

47. Dong Y, Li L, Wang L, Zhou T, Liu J, Gao Y. Preliminary study of the effects of $\beta$-elemene on MCF-7/ADM breast cancer stem cells. Genet Mol Res. 2015; 14: 2347-55.

48. Li QQ, Lee RX, Liang H, Wang G, Li JM, Zhong Y, et al. $\beta$-Elemene enhances susceptibility to cisplatin in resistant ovarian carcinoma cells via downregulation of ERCC-1 and XIAP and inactivation of JNK. International journal of oncology. 2013; 43: 721-8.

49. Vansteenkiste JF, Canon JL, De Braud F, Grossi F, De Pas T, Gray JE, et al. Safety and efficacy of buparlisib (BKM120) in patients with PI3K pathway-activated non-small cell lung cancer: results from the phase II BASALT-1 study. Journal of Thoracic Oncology. 2015; 10: 1319-27.

50. Weston CR, Lambright DG, Davis RJ. MAP kinase signaling specificity. Science. 2002; 296: 2345-7

51. Tait JF. Imaging of apoptosis. Journal of nuclear medicine. 2008; 49: 1573-6.

52. Radović N, Cucić S, Altarac S. Molecular aspects of apoptosis. Acta medica Croatica: casopis Hravatske akademije medicinskih znanosti. 2008; 62: 249-56. 